\title{
Identification of Fatty Acids in Edible Wild Plants by Gas Chromatography
}

\author{
Ali Aberoumand \\ Received: 28 September 2008 / Accepted: 27 October 2008 / Published online: 18 November 2008 \\ (C) The Author(s) 2008. This article is published with open access at Springerlink.com
}

\begin{abstract}
Human beings evolved on a diet that was balanced in the omega- 6 and omega-3 polyunsaturated fatty acids (PUFA), and was high in antioxidants. Edible wild plants provide alpha-linolenic acid and PUFA. Today, we know that omega-3 fatty acids are essential for normal growth and development and may play an important role in the prevention and treatment of coronary artery disease, hypertension, diabetes, arthritis, other inflammatory and autoimmune disorders, and cancer. Comparison of obtained results from analysis of fatty acids of edible plant oils showed that Solanum oil has the highest nutritional value because it contains high contents of linoleic acid (62.29\%) and oleic acid (8.6\%) and Asparagus oil has high nutritional value because it contains $66.12 \%$ oleic acid and 9.6\% linoleic acid. Comparison of results of this study with reported results by Artemis (2004) showed that palmetic acid (34.48\%) and estearic acid (21.71\%) contents of portulaca in this study were greater than the results reported by Artemis. Therefore, we can conclude that Solanum and Asparagus oil are edible and have good nutritive values.
\end{abstract}

Keywords Fatty Acids · Nutritive Values .

Solanum and Asparagus $\cdot$ Iran · India

\section{Introduction}

In developing nations, numerous types of edible wild plants are exploited as sources of food; hence, they provide an adequate level of nutrition to the inhabitants (Aberoumand 2008). Nutritional information is used increasingly by public agencies and agricultural industries to promote fresh produce. Consumers are looking for variety in their diets and are aware of the health benefits of fresh fruits and vegetables. Of special interest are food sources rich in antioxidants (Aberoumand and Deokule 2008). Conjugated linoleic acids (CLA) are a group of positional and geometrical isomers of linoleic acid (LA) with a conjugated double bond system. The major natural sources of CLA are fat tissues of ruminants (meat and dairy products). The cis 9 ,-trans 11 (c9, t11) isomer is the most abundant natural isomer (about 75 $90 \%$ of total CLA), which is also called rumenic acid (Gnadig et al. 2003). Studies (in vivo and in vitro) have revealed biological activities of CLA including antioxidative, anticarcinogenic, antiatherosclerotic, antidiabetogenic, and antiobesity properties, along with immune-enhancing effects (Flintoff-Dye and Omaye 2005; Wang and Jones 2004).

Different methods, such as dehydration of ricinoleic acid (Yang et al. 2002), photoproduction of CLA (Gangidi and Proctor 2004), and alkaline isomerization of LA or LA-rich oils (Berdeaux et al. 1998), are used to synthesize CLA. Alkaline isomerization of LA is usually used for commercial production of CLA containing two isomers, c9,t11 (43-45\%) and t10,c12 (43-45\%), accompanied by small amounts of other CLA isomers (Wang and Jones 2004); however, since the biological activity of the product is due to the presence of both isomers, a purification step would be necessary. Ureainclusion crystallization has been generally employed to concentrate useful polyunsaturated fatty acids and CLA in edible oils (Hayes 2006). 
Although CLA have several beneficial effects, the consumption of CLA has decreased due to the replacement of milk and animal fats by vegetable oils. Enzyme-catalyzed acidolysis is an approach to increase the CLA content in structured lipids (SL). Several researches of enzymatic interesterification of CLA with fats and oils were reported; Garcia et al. $(1998,2000)$ prepared SL from butter and fish oils with CLA by enzymatic acidolysis. Ortega et al. (2004), using a lipase, incorporated CLA in fully hydrogenated soybean oil; Lee et al. $(2003,2004)$ reported the interesterification of CLA with soybean, sunflower, and safflower oils. The altered composition of triacylglycerols in SL (incorporation of CLA) provides different changes in physical and chemical characteristics of SL compared to the initial lipid, which possibly improve the functional properties of the oil. The objective of this study was to produce high-purity CLA from safflower oil and the incorporation of this functional ingredient into canola oil to prepare CLA-rich tria-cylglycerols (TG) by enzymatic interesterification and to compare the TG with the starting lipid with respect to physical and chemical properties.

\section{Material and Methods}

\section{Collection of Samples}

Eight different types of fruits and vegetables (Alocacia indica Sch., Asparagus officinalis DC., Chlorophytum comosum Linn., Cordia Myxa Roxb., Eulophia Ochreata Lindl., Momordica dioicia Roxb., Portulaca oleracia Linn., and Solanum indicum Linn.) were collected from various localities of Maharashtra (India) and Iran. Five wild edible plants from between eight different types of fruits and vegetables in this study were collected from Iran, viz., Asparagus officinalis, Chlorophytum comosum, Codia myxa, Portulaca oleracia, and Solanum indicum were collected from Iran.

\section{Samples Preparation}

Fresh fruits and vegetables were cleaned with water and external moisture was wiped out with a dry cloth. The edible portions of the individual fruits were separated and dried in a hot air oven at $50{ }^{\circ} \mathrm{C}$ for $1 \mathrm{~h}$. The dried samples were powdered in blender for further study. Some of the plants were dried under shade so as to prevent the decomposition of chemical compounds.

\section{Chemicals and Instruments}

1. Chemicals: methanolic $\mathrm{HCl}(0.2 \mathrm{M})$, methanolic $\mathrm{NaOH}$ $(0.1 \mathrm{M})$, heptadecanoic acid $(17: 0)$ as internal standard, $0.5 \mathrm{~N} \mathrm{KOH}$ solution $(20 \%$ ethanol, $20 \mathrm{~mL})$, hexane
(40 mL), 0.5 NKOH (20\% ethanol), saturated $\mathrm{NaCl}$ $(10 \mathrm{~mL})$ solution, and anhydrous sodium sulfate column

2. Instruments: gas chromatograph (CP9002; Chrompac), rotary vacuum evaporator, a separatory funnel with a stopcock, and Soxhlet apparatus

\section{Extraction of Plant Oil}

The oils were extracted using hexane as solvent. Hexane $(1,500 \mathrm{~mL})$ was added to $500 \mathrm{~g}$ of milled plants and extraction was performed for $24 \mathrm{~h}$ at room temperature; this operation was done twice to complete the oil extraction from the plants. The solvent were then removed by rotary vacuum evaporator and the plant oils were stored in a dark container in a refrigerator for the subsequent steps.

\section{Determination of Fatty Acids of Plant Oils}

To determine the fatty acid profile of plant oil, the oil was methylated according to the AOAC method. Methylated samples $(1 \mathrm{~mL})$ were injected into a gas chromatograph (CP9002; Chrompac) equipped with a flame ionization detector and the fatty acid methyl esters were separated using FFAP-CB fused-silica WCOT $(25 \mathrm{~m} 60.32 \mathrm{~mm}$ $60.3 \mathrm{~mm}$ ) and helium gas as a carrier with an inlet pressure of $75 \mathrm{kPa}$. The temperature program was as follows: increasing from 40 to $100{ }^{\circ} \mathrm{C}$ at a rate of $107{ }^{\circ} \mathrm{C} /$ min and holding for $0.2 \mathrm{~min}$, then increasing to $240{ }^{\circ} \mathrm{C}$ at $257{ }^{\circ} \mathrm{C} / \mathrm{min}$ and holding for $30 \mathrm{~min}$ at $240{ }^{\circ} \mathrm{C}$. The temperatures of the injector and detector were 230 and $250{ }^{\circ} \mathrm{C}$, respectively.

\section{Results and Discussion}

Comparison of obtained results from the analysis of fatty acids of edible plant oils showed that Solanum oil has the highest nutritional value because it contains high contents of LA and oleic acid, Asparagus oil has high nutritional value, Alocacia oil has medium nutritional value, and Portulaca oil has low nutritional value because it contains only saturated fatty acids such as estearic acid and palmetic acid. Any edible plant oils contain linolenic acid (Figs. 1, 2, 3, and 4).

Paola Benatti et al. (2004) reported that LA and linolenic acid contents in Asparagus and Portulaca was $70 \mathrm{mg} / 100 \mathrm{~g}$, $6 \mathrm{mg} / 100 \mathrm{~g}, 89 \mathrm{mg} / 100 \mathrm{~g}$, and $405 \mathrm{mg} / 100 \mathrm{~g}$. LA and linolenic acid contents of Asparagus and Portulaca in this study were not detected. Comparison of results reported by Paola Benatti et al. with results of this study showed that 


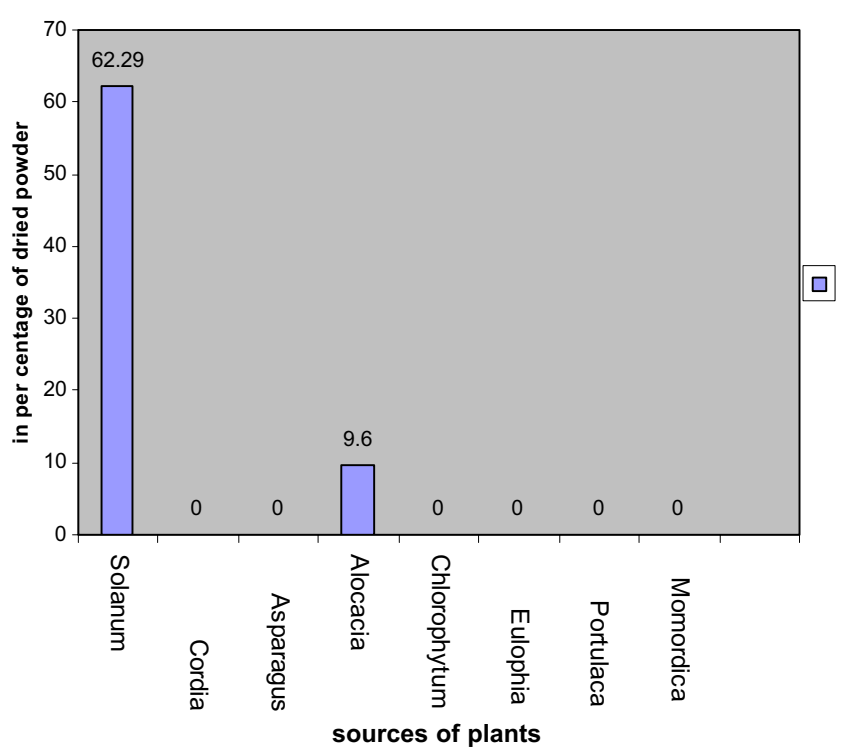

Fig. 1 LA contents of eight edible plants

LA and linolenic acid contents of Asparagus and Portulaca obtained from the work of Paola Benatti et al. was greater than the reported results.

Artemis (2004) reported palmetic acid (0.81) and estearic acid (0.20) contents of Portulaca in milligrams per gram of wet weight. Comparison of results of this study with results reported by Artemis (2004) showed that palmetic acid (34.48\%) and estearic acid (21.71\%) contents of portulaca in this study were greater than the results reported by Artemis.

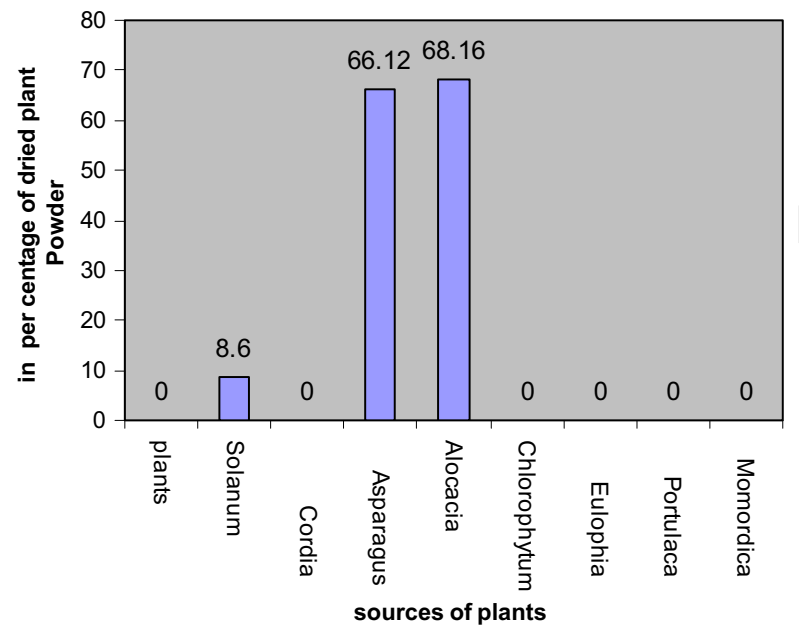

Fig. 2 Oleic acid contents of eight edible plants oil

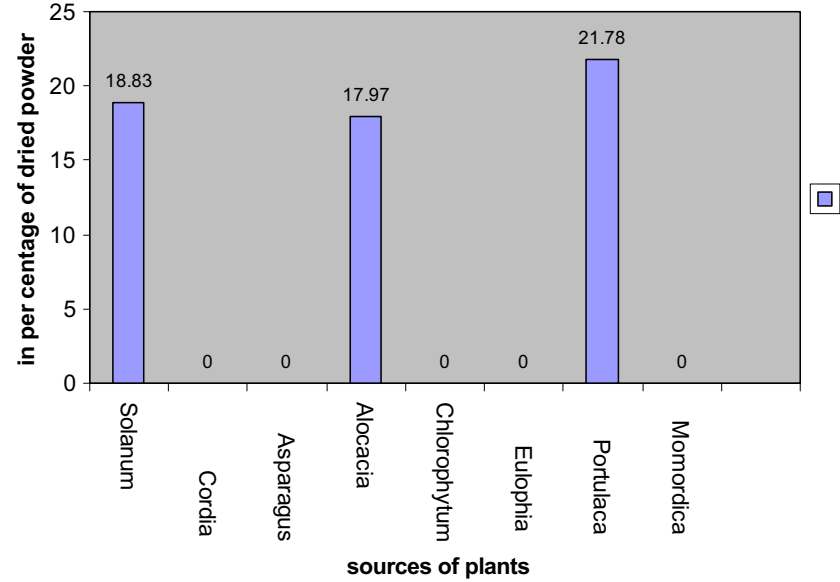

Fig. 3 Estearic acids contents of eight edible plants

\section{Concluding Remarks}

Studies on wild edible plants relative to the omega-3 fatty acids and antioxidant content are being carried out in various parts of the world. As expected, they show enormous variation in the content of both omega-3 fatty acids and antioxidants due to variation in climatic conditions and cultivars. In developing new sources of food, the study of the dietary composition of wild edible plants is essential. Their cultivation should lead to increased production of plants rich in omega-3 fatty acids and antioxidants, both of which reduce the risk of chronic diseases.

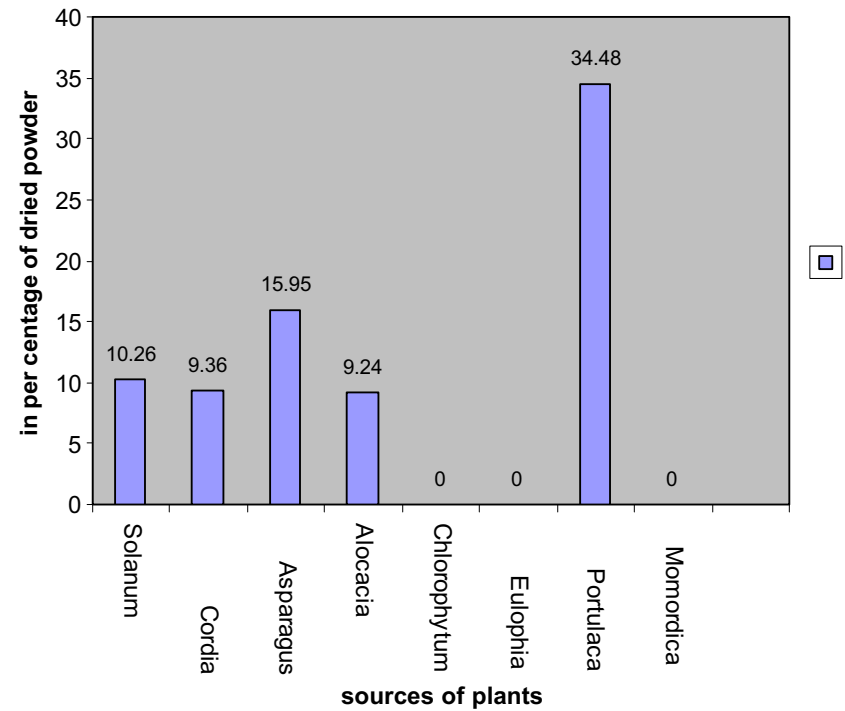

Fig. 4 Palmetic acids contents of eight edible plants 
Acknowledgements The authors are grateful to the head of the Department of Botany, University of Pune, for providing the necessary laboratory facilities and for encouragement. The first author is thankful to the head of the Department of Food Science and Technology of Ramin Agricultural University of Iran.

Open Access This article is distributed under the terms of the Creative Commons Attribution Noncommercial License which permits any noncommercial use, distribution, and reproduction in any medium, provided the original author(s) and source are credited.

\section{References}

Aberoumand A (2008) Nutritional evaluation of edible portulaca oleracia as plant food. Food Anal Methods. doi:10.1007/s12161008-9049-9

Aberoumand A, Deokule SS (2008) Determination of elements profile of some wild edible plants. Food Anal Methods. doi:10.1007/ s12161-008-9038-z

Artemis PS (2004) The omega-6/omega-3 fatty acid ratio, genetic variation, and cardiovascular disease. Asia Pac J Clin Nutr 17:131-134

Berdeaux O, Voinot L, Angioni E, Juaneda P, Sebedio JL (1998) A simple method of preparation of methyl trans-10, cis-12 and cis9,trans-11 octadienoates from methyl linoeate. J Am Oil Chem Soc 75:1749-1755

Flintoff-Dye NL, Omaye ST (2005) Antioxidant effects of conjugated linoleic acid isomers human low-density lipoproteins. Nutr Res 25:1-12 doi:10.1016/j.nutres.2004.10.003

Gangidi RR, Proctor A (2004) Photochemical production of conjugated linoleic acid from soybean oil. Lipids 39:577-582
Garcia HS, Storkson JM, Pariza MW, Hill CG (1998) Enrichment of butteroil with conjugated linoleic acid via enzymatic interesterification (acidolysis) reactions. Biotechnol Lett 20: 393-395

Garcia HS, Arcos JA, Ward DJ, Hill CG (2000) Synthesis of glycerides containing n-3 fatty acids and conjugated linoleic acid by solventfree acidolysis of fish oil. Biotechnol Bioeng 70:587-591

Gnadig S, Xue Y, Berdeaux O, Cheardigni JM, Sebe-dio JL (2003) Conjugated linoleic acid (CLA) as a functional ingredient. In: Saadholm TM, Saar-ela M (eds) Functional dairy products. CRC, Cambrige, pp 263-297

Hayes DG (2006) Effect of temperature programming on the performance of urea inclusion compound-based free fatty acid fractionation. J Am Oil Chem Soc 83:253-259

Lee JH, Kim MR, Kim HR, Kim IH, Lee KT (2003) Characterization of lipasecatalyzed structured lipids from selected vegetable oils with conjugated linoleic acid: their oxidative stability with rosemary extracts. J Food Sci 68:1653-1658

Lee JH, Shin JA, Lee JH, Lee KT (2004) Production of lipasecatalyzed structured lipids from safflower oil with conjugated linoleic acid and oxidation studies with rosemary extracts. Food Res Int 37:967-974

Ortega J, Lopez-Hernandez A, Garcia HS, Hill CG (2004) Lipasemediated acidolysis of fully hydrogenated soybean oil with conjugated linoleic acid. J Food Sci 69:1-6

Paola B, Gianfranco P, Raffaella N, Menotti C (2004) Polyunsaturated fatty acids: biochemical, nutritional and epigenetic properties. J Am Oil Nutr 23(4):281-302

Wang YW, Jones PJH (2004) Conjugated linoleic acid and obesity control, efficacy and mechanisms. Int J Obes 28:941-955 doi:10.1038/sj.ijo.0802641

Yang L, Huang Y, Wang HQ, Chen ZY (2002) Production of conjugated linoleic acids through $\mathrm{KOH}$-catalyzed dehydration of ricinoleic acid. Chem Phys Lipids 119:23-31 doi:10.1016/ S0009-3084(02)00052-X 